\title{
FROM A POINT CLOUD SURVEY TO A MASS 3D MODELLING: RENAISSANCE HBIM IN POGGIO A CAIANO
}

\author{
C. Bolognesi ${ }^{1}$, S. Garagnani ${ }^{2}$ \\ ${ }^{1}$ Dept. ABC, Politecnico di Milano, via Ponzio 31, Milano, Italy - cecilia.bolognesi@polimi.it \\ ${ }^{2}$ Dept. of Architecture, University of Bologna, viale Risorgimento 2, Bologna, Italy - simone.garagnani@unibo.it
}

\author{
Commission II, WG II/8
}

KEY WORDS: Point clouds, Digital accuracy, Parametric mass modelling, HBIM, Renaissance architecture, Scan to BIM

\begin{abstract}
:
This paper introduces some studies developed regarding the Medicea Villa at Poggio a Caiano, in Italy. The monumental building was built by Lorenzo de' Medici and his heirs following the design of the famous architect Giuliano da Sangallo, between 1485 and 1520. The Villa embodies many of the typical features of the Italian Renaissance, added a monumental double circular stairway in the front façade during neoclassical times, heading to the upper balcony surrounded by a balustrade. The Villa was surveyed taking advantage of Terrestrial Laser Scanning and Digital Photogrammetry, in order to produce a detailed model to be translated into a HBIM digital prototype then. The Scan-to-BIM approach was obtained with a generation of semantics and components proper of Sangallo's architectural grammar, first of all defining the object, then geometry, and then their parametrization. This process led to a model of the exteriors, used to better understand the architectural composition of the volumes, to make some hypothesis on its shape according to the original architect's drawing in the Taccuino Senese, on its general structural behaviours, to understand the limits of a process and the perspective of a research that goes from a digital survey to the HBIM environment.
\end{abstract}

\section{INTRODUCTION}

\subsection{Aims of this research}

A first aim of this research is the creation of a complete and describable pipeline that comes from the TLS and photogrammetric image-based survey of a Renaissance Architecture, considers the integration of different survey and measurement techniques, the verification of the real achieved Level of Accuracy, forms a point cloud to be imported into a BIM environment.

The workflow follows with the modelling of of parametric components not available in the commercial platform libraries to create parametric 3D of the existing to be consulted for any activity required: from the study of the building itself to the comparison with other architecture examples, from a study of the building decay and pathologies to a renovation project. (Chiabrando et al., 2017).

The research wishes to investigate how much can be reversed from the monument itself into a new digital model in a particular case study, taking care of the accuracy of the model if compared to the built environment. The gap between the existing and the model is considered as the boundary to be investigated by the following researches.

\subsection{Digital modelling of historical architecture for research}

The modalities of digital survey for the modeling of the existing domain have changed a lot the perspective of knowledge of cultural heritage especially in terms of expected output. (Apollonio et al. 2010).

Nowadays if you use a photogrammetric or laser scanner measurement method the workflow to manage and process the model is the same for both technologies and you expect the same type of output: the point cloud model can be used to generate two-dimensional technical drawings to extract sections realized in specific software of reverse engineering (i.e. Polyworks, Geomagic Wrap, etc.) or directly into CAD environments: it is possible to cut the model with planes or boxes and extract point sections useful to draw technical graphic representations. In the same way you can obtain from a textured polygonal model orthographic images processed with high detail and resolution often obtained after good processes of mesh repair and decimation.

When the output is the generation of a BIM model from an existing building that is a polygonal model organized by parametric objects with attributes, the perspective of the pipeline changes. HBIM constitutes a solution to study and preserve heritage across centuries and it can become a great tool to preserve architecture and its memory.

Our task is developing its potential in relation to the objectives that arise, considering the accuracy of the method (Bianchini, 2014), scientific parameters in its capacity of analysis, needed skills, time consume, ability to spread among scholars). As scientists, we can't forget that the components of this pipeline are of various types: as a result of a survey operation they are first of all qualitative elements that engage scientist's sensitivity and interpretative skills, shaped by measure and capability of techniques.

Many skills are required to be integrated in the process, each of them is subject to personal comment that could be shifted in our model: in each step of the process alert has to be deeply considered. 


\section{HISTORIC AND SCIENTIFIC BACKGROUND}

\subsection{The Villa in Poggio a Caiano: a case study}

The first evidence of the existence of the Villa is a medieval building in Poggio bought around 1470 by Lorenzo de' Medici to be restored to live in with his family.

The current building is probably the result of a series of additions to the previous one, which occurred very rapidly until a first stop in 1494 when the Medici family was driven out of Florence, two years after Lorenzo's death.

The building of the early 1490 s is already a tripartite building, with loggias, porticoes and railings. Some of the existing parts in the overlapping of the constructions lead to think that they were cleverly used as raw materials to be built on; the hypothesis is certainly supported by some dimensional inconsistencies, material discontinuities, recent thermographs that show more than a buffered gap and new openings. The innovative typology of the building marks a fracture between the previous noble manor, fortified and introvert, and a new Villa concept, a Renaissance one, open with its elevations towards the landscape with a composition of inner spaces related to the exterior ones strengthened by the presence of porches or loggias. For the first time in his life, Giuliano da Sangallo uses a porch around the whole main core of the Villa at the ground floor and a classical loggia at the first floor; the porch acquires the meaning of a linguistic code. The last change of the villa of 1807, is evidenced by the inclusion of a circular staircase and entrance built to create a covered corridor where to accommodate the carriages, once eliminated the straight ramps perpendicular to the facade created by Giuliano da Sangallo himself.

In the field of historical architectural survey, terrestrial laser scanning technology and photogrammetric applications are subject to continuous innovation and progress; these acquisition methodologies allow the creation of $3 \mathrm{D}$ point clouds, capable of a detailed reproduction of the captured scene, with which interact for inspection and metric interrogation. More precisely, the primitive return of a three-dimensional survey is represented by a set of points that reproduce the surface of the measured object (Apollonio et al., 2012).

The advantages compared to traditional survey techniques can be found in the high detail of the $3 \mathrm{D}$ reconstruction, in the precision of the measurements, in the speed of data acquisition and in the flexibility and adaptability to different situations and needs. Close-range photogrammetry can be effective especially if supported by the use of terrestrial laser scanning and both systems have many applications, especially in the field of heritage documentation, architectural restoration, and structural analysis. Once the 3D point cloud is generated, all the studies required to develop a complete morphological analysis can be performed identifying areas of degradation, distinguishing the original areas from restored ones, identifying the historical stratifications and the different materials, etc.

In the last years the possibility offered by BIM-oriented software to be interoperable with different dedicated software applications, to use the BIM model as a database to store different kinds of data, has pushed research forward; this research has been further increased by the recent possibility of importing the point cloud into BIM-oriented software, allowing an immediate comparison between standardized object and the captured cloud (Adami et al. 2017). One challenge is the complete definition of as much as possible BIM objects from the $3 \mathrm{D}$ point cloud, originally born with a specific and unique concept of standardization (Chiabrando et al., 2017) as a base for new HBIM model.
For the fact that BIM software works with standardized family the possibility to build new families where each element is categorized is very real, as real is a never ending and time consuming activity to do it. The accuracy of the model must face the complexity and stiffness of commercial software.

\subsection{Extended surveys and architectural representation}

Together with the Barberini Code and other documents, the "Taccuino Senese" is part of the corpus of drawings left to us by Giuliano da Sangallo, now in the Library of the Intronati in Siena. It is a collection of numerous drawings and sketches concerning both elements and architectural orders studied by the architect, together with some of his projects. Among them there is the drawing of the ground floor of the Villa in Poggio a Caiano (Figure 1), perhaps the only one that represent the project originally conceived by Sangallo.

This document is the clear explanation of the proportion of the whole building, considered in its floor level as in the renaissance elevation derived; the original sketch allows to extrapolate the module of the building and the rhythm of the pillars and the porticoes. The plant was planned according to simple relations among the main parts of the buildings: main core and secondary ones, but combined in a rather articulated way. The unit of measurement is the Florentine "braccio" used in Tuscany till 1877.

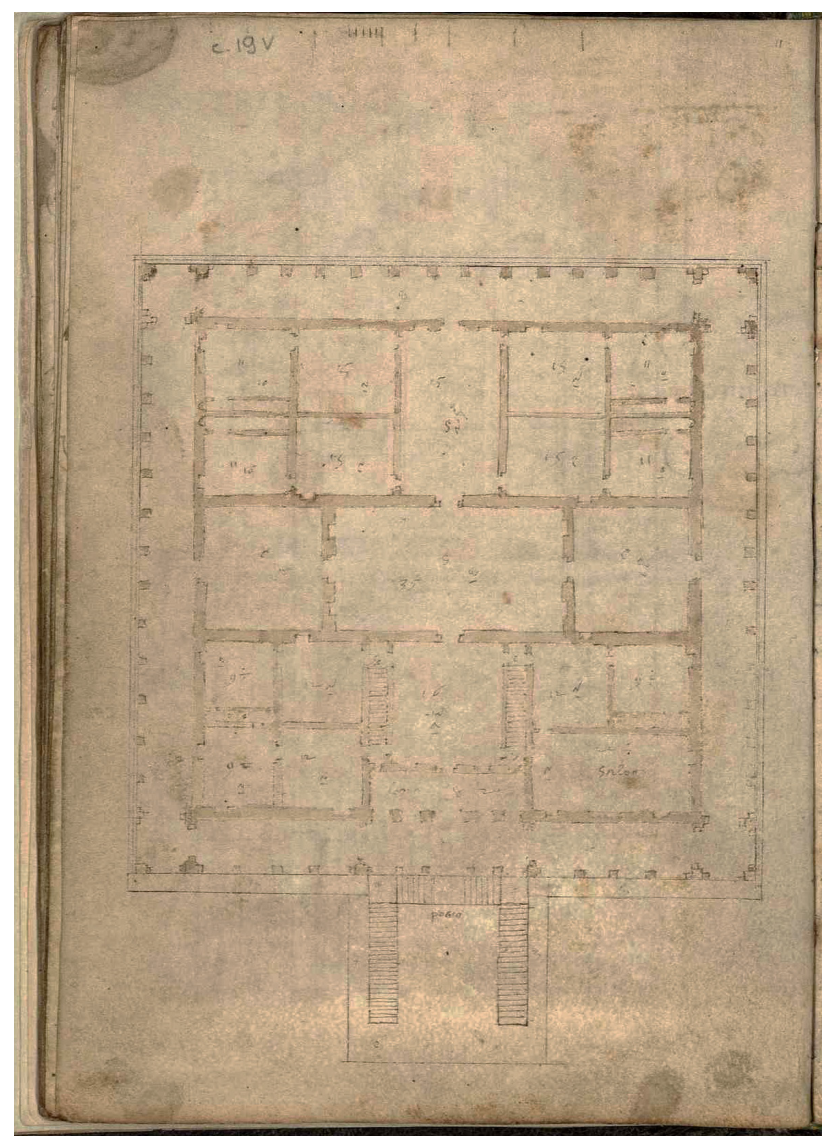

Figure 1. The original drawing by Giuliano da Sangallo."Progetto in pianta per la Villa Medicea Poggio a Caiano" as portayed in the "Taccuino Senese". 
As an original document this plan has been investigated as a parameter to check differences between the original design intent of Sangallo and the present building in Poggio a Caiano (Frommel, 2015)

\subsection{Historical buildings knowledge: the HBIM process}

The scientific literature has delved into Historic Building Information Modeling (HBIM) since its introduction in 2009, by Maurice Murphy, Eugene McGovern and Sara Pavia (Murphy et al., 2009).According to their original definition, HBIM has to be considered mainly as "the procedure of remote data capture using laser scanning and the subsequent processing required in order to identify a methodology for creating full engineering drawings (orthographic and $3 D$ models) from laser scan and image survey data for historic structures". It was basically adopted as a methodology in which accurate surveys were compared to an already prepared library of architectural components; when a specific object (represented in GDL language into the ArchiCAD environment) would fit the related portion of the point cloud, the semi-automatic superimposition of the element could contribute in the authoring of a geometric model meant to simplify shapes and create a lighter 3D representation. Many further research works considered this approach more generally as BIM modeling for existing buildings, regardless of the methodology used to acquire any kind of data related to them. Later, the introduction of the term Scan-to-BIM (or Point-to-BIM) was used to indicate the workflow beginning from the generation of a point cloud then translated (most of the times with time consuming human intervention) into "in-place" geometric objects (i.e. not relying on libraries), in order to exchange building data among practitioners and designers through the abstract 3D representation (Valero et al., 2011). The final goal of both the approaches is the production of a standardized geometric threedimensional model, in which all data linked to the "macro and micro" architectural systems can be shared following specific data format such as IFC or other proprietary data-schemes. The approach followed in this research work was partly derived from Scan-to-BIM, while most of the components investigated on the Sangallo's Villa were reproduced in the digital domain in form of geometric libraries, not authored as general components but as parametric and dedicated elements instead, in order to better fit the actual geometry. The HBIM methodology adopted, this way, combined the starting point cloud accuracy retracing with a production of libraries directly connected to the Sangallo's grammar.

\section{DATA ACQUISITION}

\subsection{Planning the survey: preliminary approach to a wide and complex data collection}

The Villa's exteriors were surveyed using both Terrestrial Laser Scanning (TLS) and digital photogrammetry (DP): while the first technique granted a reliable metric model, the second one was mainly dedicated to architectural details and textures, in order to document materials, damages and preservation.

A preliminary plan was prepared to allow a successful survey campaign, taking into account geometries of the porch and the loggia, which are the indispensable tool for a wider reflection on the monument and to work on it from a scientific perspective: the campaign was prepared for the digital photogrammetry (Figure.2) as well as for the terrestrial laser scanning (Figure 3).

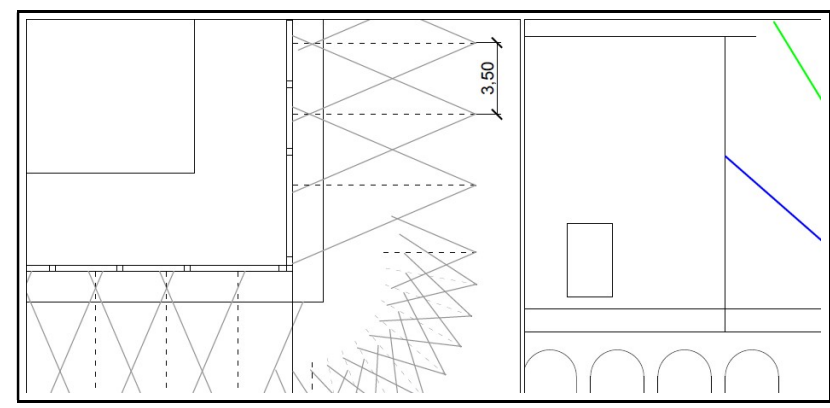

Figure 2. Scheme for acquisition points with overlapping of images in the project for the photogrammetric survey.

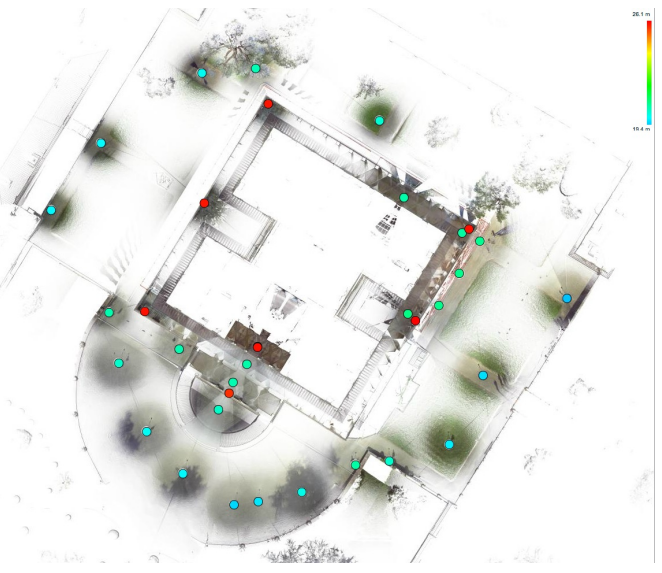

Figure 3. The main survey plan, indicating the positions of all the 35 acquired scans around the Villa.

Some proportional systems or even the choice of a typological element such as the pillar or the column, in fact, can be properly evaluated in the light of an accurate survey model.

Documentary sources to investigate the geometry of the portico have been investigated both in the literature provided by the Taccuino Senese (G. da Sangallo), and in some previous buildings by Sangallo himself. The survey was performed, this way, also to investigate more and more geometric and constructive criteria chosen by the architect.

For the best success of the photogrammetric survey of porch and loggias, an accurate shooting project was drawn. The morphology of the portico contains elements of increasing difficulty for the photogrammetric restitution: the thirteen vaults on each side, whose cross-shaped surfaces lean on rectangular bases, featured a white and uniform background, difficult to be isolated by software.

Furthermore, the background of the portico has different niches and openings. Towards the outside, the shooting was forced against backlit conditions that required the use of flashes on the entire part of the survey for the darkened porch.

\subsection{Terrestrial laser scanning and digital photogrammetry of the Villa}

TLS techniques were applied, registering almost 35 scans outdoor the monument: a general referenced point cloud related to the Villa was authored taking advantage of Faro Scene 5.0 software, processing colour raw files collected by a Focus3D 
Cam2 phase shift laser scanner device (3D point accuracy up to 2 millimetres; working distance $=0.6-150$ meters). The Ground Sample Distance (GSD) was included between 4 and 18 millimetres.A change of schedule, however, had to be done during the on-site survey, since several unexpected obstacles like scaffoldings, warning taped areas and arches closed to the public use were found. This way, DP was used as a complement to TLS, due to the better handling of camera devices.

The maximum distance $\mathrm{D}$ of the captures from the object is calculated basing on the focal length and camera sensor size (D $=\mathrm{GSD} \times \mathrm{f} /$ pixel size); the sensor size of the camera and the focal length and the morphology of the object determine the distance between two points that depends in order to satisfy horizontal covering, and consequently the number of images needed, whereas an overlap of $60 \%$ consecutive shots is always recommended and a vertical overlapping should be around 20$30 \%$. For the Villa it was decided to accept an error within the centimetre, assuming an average scale of representation of 1:50, with a degree of precision equal to 4 as a divisor. It follows that the GSD, which represents the resolution and the detail of final $3 \mathrm{D}$ reconstruction, is: $\mathrm{GSD}=1 \mathrm{~cm} / 4=2,5 \mathrm{~mm} / \mathrm{pixel}$, that is each pixel of the image represents $2.5 \mathrm{~mm}$ of the actual object detected.

While the laser scanning campaign was carried out mostly in target-less mode, registering scans later using cloud-to-cloud algorithms (Brilakis et al., 2010), many circular targets were provisionally placed all over the Villa for photogrammetric purposes (Hajian, 2010). The mutual distance of the pillars gave the decisive geometric constraint, which is equal to 3.60 meters. This distance was considered as the baseline of the photo shoot, with a proper horizontal and vertical overlapping of close images.

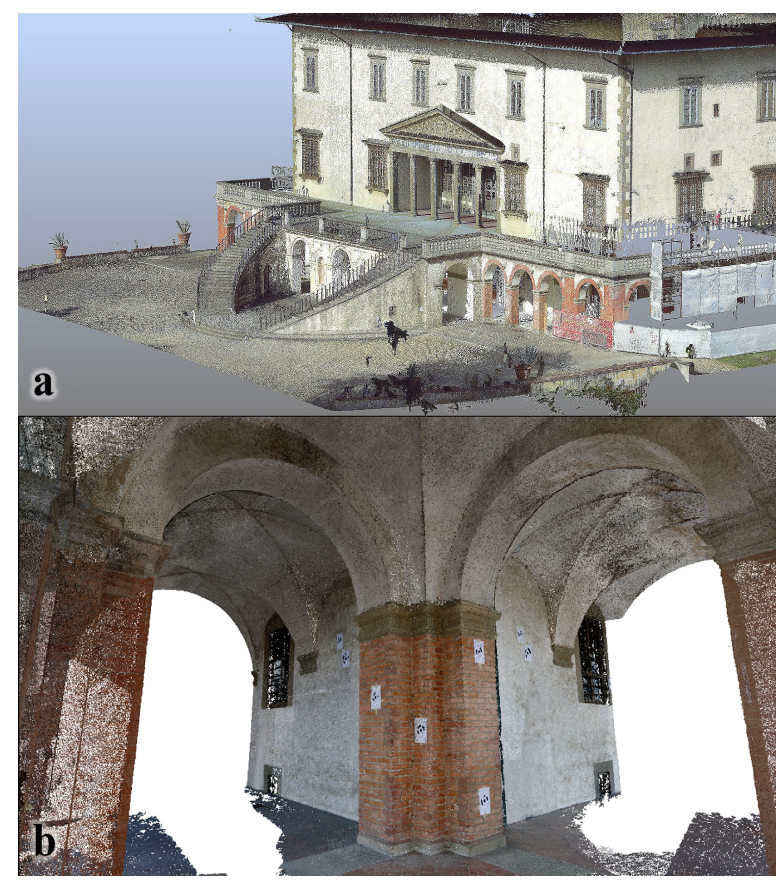

Figure 4. An overall point cloud generated by TLS techniques (a) and a detail acquired using DP (b).

The image files have been kept at maximum resolution and minimum compression with automatic focus.
With a focal length of $18 \mathrm{~mm}$ and a wheelbase of $1.6 \mathrm{~m}$ the overlapping was $65 \%$; many of the bases are by the pillars or in the middle of the span and the optimization of the photo shoot project with the right length allowed to produce only 5 images for span; this was allowed by horizontal orientation of the camera to capture with one shot the entire vault and two vertical photos for the first lateral covering (Figure $4 a$ and $4 b$ ).

\section{DATA PROCESSING AND HBIM APPROACH}

\subsection{Getting the point cloud output}

The porch and the loggia in Poggio a Caiano were modelled following a working pipeline consisting in four stages during which they were surveyed with high definition techniques (data collection stage), the survey results were processed and registered in overall point clouds (data processing stage), then architectural elements were identified and properly segmented (semantic abstraction stage) and finally they were replicated in form of parametric components in a BIM software environment (BIM modeling stage).

After the first two stages of the process the resulting point cloud, even if accurate, is a collection of unstructured geometric entities; in order to better understand all the relationships among components, it was properly segmented into many domains pertaining the architectural elements whose attributes and properties would have been developed later along the process.

Since a predefined architectural grammar composed by Sangallo's digital elements, an HBIM approach as meant by its original definition (Murphy et al., 2013), was partially pursued. Instead of superimposing digital libraries of components to the point clouds, the digital parametric objects were inferred retracing geometries over the survey references.

\subsection{Semantics and parametric modelling}

Taking advantage of the generated and segmented point clouds, many details of the main façades and the porticos surrounding the Villa were analysed and replicated, following a Scan-toBuilding Information Modeling approach.

Even though BIM is a process mainly pledged to new constructions (Eastman et al., 2008), whose information among actors is shared using digital models, the scientific literature proved it can be extremely useful on existing cultural heritage as well, regardless of the age of the investigated context.

HBIM models rely on a fundamental feature, which is represented by their parametric components that are self-aware of their architectural identity and conscious of their mutual semantic interactions (Dore et al., 2012).

This way, a HBIM model is an ideal database where elements, from the whole building to the smallest detail, can be related to heterogeneous data, keeping track of their relationships and roles in the global construction. A point cloud model, on the contrary, cannot be proficiently used to carry out simulations or quantity take-offs, even if its geometrical precision is relevant in order to author an accurate digital model (Benedetti et el. 2011). In other words, a HBIM model needs to be interactively prepared from a point cloud, creating a parallel geometric abstraction where the metric accuracy of single object can be extrapolated if needed by the cloud itself, which keeps on integrating the database even after the digital retracing with parametric components.

A parametric model, in fact, is a representation that binds the architecture of its components to numerical variables (Lynn, 
1998), which can be modified according to semantic relationships (Gerber, 2007, an architrave is always connected to the pillars supporting it, even if these change their initial shape), mathematical formulas (Aubin, 2013, knowing an ideal proportion, it can be attributed to the parameters in form of equations or polynomials) or variational constraints (Aubin, 2013, Oxman et al., 2015, parametric changes can only be made under certain conditions, following explicit mathematics that exclude possible alternatives).

Beginning from the survey data, parametric modeling was set up resulting in a coherent grammar able to describe the architectural details and their general composition system in a parametric approach that was supported by the software Autodesk Revit 2018.2 (Figure 5).Revit's parametric engine, unlike a generic CAD software, manages the construction of a three-dimensional model by verticalizing the result to the architectural scale: it is not possible to use this modeling environment as an electronic drafting tool, since its ultimate goal is the virtual construction of a digital prototype of the investigated building.

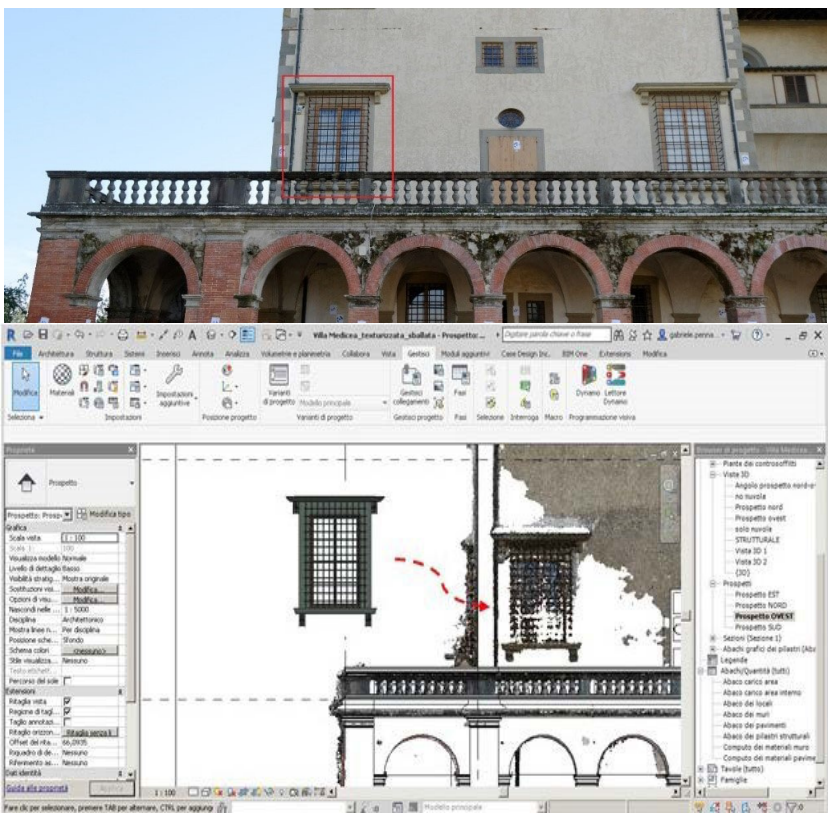

Figure 5. An architectural component (historic window) generated with point cloud retracing (Scan-to-BIM approach), and in the complete model by comparison with the point cloud (HBIM approach).

\section{FINAL RESULTS AND ACHIEVEMENTS}

\subsection{From the HBIM model to the knowledge of the Villa}

Issues that emerge from the application of parametric and semantic HBIM modeling are represented by the time required to process a correct survey at first and a proper introduction of digital parameters later in the modeling stage, in order to dinamycally change morphologies and let then resemble the best possible way the actual geometry. The process is still not automatic and it requires an adequate preparation in terms of knowledge for the graphic engine and the variational binding system. A too low number of parameters does not bring advantages in terms of architectural reference values, while a system of overabundant or poorly distributed constraints does not allow the parameters to explicate correct geometries. In general, constraints and parameters were prepared at first for the main elements like the arches, while subdivisions and details (such as capitols or mouldings) were added to the former, without introducing other dedicated variable parameters. In this way, by making grammar choices from global parameters, the proportional relationships were highlighted with the association only of numerical rules and geometries inferred by the point clouds.Considering the model as a collector of data related to the Villa, the point cloud is stil available: the parametric representation can be really considered as an abstraction, which serves as an interpretation of building techniques as well as a geometric index for extended data contents.

\subsection{Digital reconstruction}

The architectural composition of the Villa is the result of the semantics proper of every single component assembled: the HBIM model authed, even if dedicated to exteriors only by now, embodies the functions of a digital prototype and it can be proficiently used to host historic data (pictures documenting the preservation state of materials and plasters were, for example, linked to walls and pillars), to gather information on the original building techniques and modifications occurred over the years in materials and structures, and to perform simulations and analysisThe building's main stairway in the front façade, for istance, was not built according to the original plan by Giuliano da Sangallo and changed during the life time of the monument: the model generated could be likely used as a knowledge framework to simulate the architect's intent, with two different straight staircases reaching the first balcony instead of the actual ones (Figure 6).

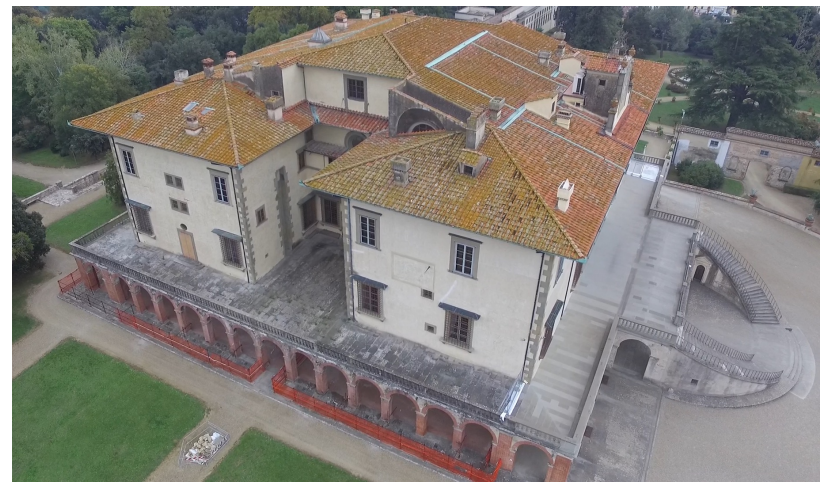

Figure 6. The Villa in Poggio a Caiano with the double circular staircase (image by the authors)

Furthermore, the model was experimentally already used to better understand the structural behaviours of the outside brick walls (Figure 7).

The exterior boundary and all the significant structural abstractions needed by a Finite Element Modeling software were loaded directly from the HBIM geometric database authored in Revit, imposing loads and constraints according to the relationships among building elements. Even if it would have been much more significant a complete analysis considering bot exterior and interior walls, this first attempt proves the versatility and the updating possibilities of the digital reconstruction. 


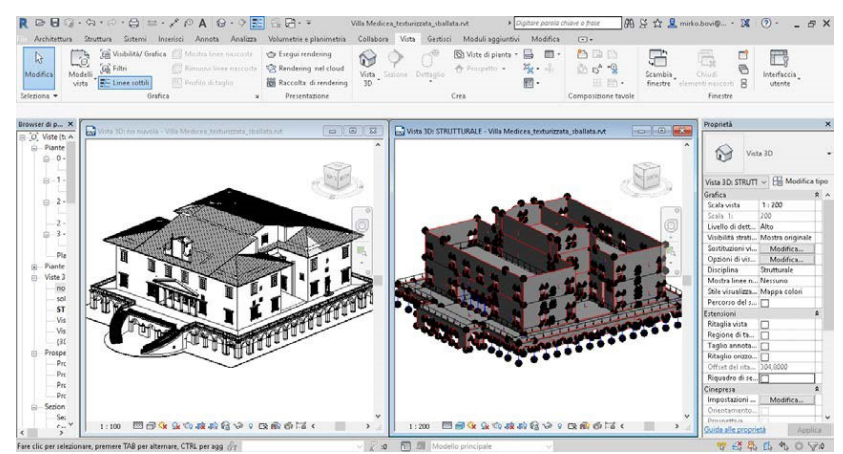

Figure 7. The structural analytical model produced straight from the HBIM prototype derived from the point cloud. Loads and constraints were embedded according to well-known Renaissance building techniques.

\section{CONCLUSION}

A HBIM digital model is conceived to improve information quality and quantity as the knowledge on the existing building grows; when this approach is applied to an existing monument, just like Villa Medicea in Poggio a Caiano, data collection becomes a complete digital repository aimed at the knowledge of the architectural heritage.

This paper proved that the methodology and its tools have certainly to be improved in terms of accuracy, reliability and automation; the theme of model accuracy is still open and the expected precision of a BIM model perhaps a case by case theme still in progress

But among winning aspects the BIM modelling gives the possibility to implement data set making them accessible to following studies and implementation.

Here we understand that the approach based on a mixed Scanto-BIM and a HBIM comparison with digital libraries of elements modelled in-place can be proficient and successful in gathering data even on wide and complex monuments.

Future perspectives on this work are focused on the survey and the modeling of the whole building, since a HBIM repository has to be referred to the complete investigated context, in order to better understand how it was built and how Sangallo solved many issues. This proposal highlights many of the advantages and limits connected with the HBIM transition applied on existing monumental sites, considering it a further development in methodologies and techniques aimed at the cultural heritage preservation.

\section{ACKNOWLEDGEMENTS}

This paper is a part of a collective investigation on the Sangallo's building carried out by the authors and by students Mirko Bovi and Gabriele Pennacchio with Eleonora Ferraretti, Alessandro Mai e Yuri Seti.

The research is part of a general agreement drawn up between the faculty of Histoire de l'art de la Renaissance École Pratique des Hautes Études - Sorbonne, with Sabine Frommel, and AUIC School of Architecture Urban Planning Construction Engineering at the Politecnico of Milano with Cecilia Bolognesi, deduced from a previous agreement between Sorbonne with Alma Mater Bologna.

\section{REFERENCES}

Adami,A., Scala,B., Spezzoni,A, 2017. Modelling and accuracy in a BIM environment for Planned Conservation: the apartment of Troia of Giulio Romano. . International Archives of the Photogrammetry, Remote Sensing and Spatial Information Sciences, Vol. XLII-2/W3

Apollonio, F. I., Gaiani, M., Remondino, F., 2010. Una pipeline per l'acquisizione di dati 3D. In: Model. Digit. 3D Archeol. Caso Di Pompei. Edizioni della Normale, Pisa.

Apollonio F. I., Gaiani, M., Sun, Z. 2012. BIM-based modeling and data enrichment of classical architectural buildings. «SCIRES-IT» 2(2), pp. 41-62.

Aubin, P., 2013. Renaissance Revit: Creating Classical Architecture With Modern Software. Createspace Independent Publishing.

Benedetti B., Gaiani M., Apollonio F.I., 2011. Teorie per rappresentare e comunicare siti archeologici attraverso modelli critici, «SCIRES-IT», 1(2), pp. 33-70.

Bianchini, C., 2014, Modeling, Interpretation as multidisciplinary components of Aknowledge System, «SCIRES-IT», 4(1), pp. 15-24.

Brilakis, I., Lourakis, M., Sacks, R., Savarese, S., Christodoulou, S., Teizer, J. and Makhmalbaf, A., 2010. Toward automated generation of parametric BIMs based on hybrid video and laser scanning data. Advanced Engineering Informatics, 24(4), pp. 456-465.

Chiabrando F., Lo Turco M., Rinaudo F., 2017. Modeling the decay in an HBIM starting from 3D Point Clouds. International Archives of the Photogrammetry, Remote Sensing and Spatial Information Sciences, Vol. XLII-2/W5.

Donetti, D., Faietti M., Frommel S., 2017. Giuliano da Sangallo. Disegni degli Uffizi. Firenze: Giunti Editore.

Dore C., Murphy M., 2012. Integration of historic BIM (HBIM) and 3D GIS for recording and managing Cultural Heritage sites, in 18th International Conference on Virtual Systems and Multimedia (VSMM), Proceedings (Milano 2012), IEEEXplore digital library, pp. 369-376.

Eastman, C., Teicholz, P., Sacks, R., Liston, K., 2008. BIM Handbook: A Guide to Building Information Modeling for Owners, Managers, Designers, Engineers and Contractors, Wiley Publishing.

Frommel S., 2014. Giuliano da Sangallo architetto, Edifir, Firenze.

Giuliano da Sangallo, Progetto in pianta per la Villa Medicea a Poggio a Caiano, Siena, BI, ms. S. IV. 8 (Taccuino Senese), f. $19 \mathrm{v}$. Image publicly available at https://www.akgimages.fr/archive/-2UMDHUWW3TZHS.html (4 April 2018).

Hajian, H., and Becerik-Gerber, B., 2010. Scan to BIM: Factors affecting operational and computational errors and productivity loss. 2010 - 27th International Symposium on Automation and Robotics in Construction, ISARC 2010, pp. 265-272. 
Lynn, G., 1998. Folds, bodies \& blobs: collected essays. Brussels: La lettre volée.

Murphy, M., McGovern, E., Pavia, S., 2009. Historic building information modelling (HBIM), Structural Survey, 27(4), pp. 311-327, https://doi.org/10.1108/02630800910985108

Murphy, M., McGovern, E., Pavia, S., 2013. Historic building information modeling - Adding intelligence to laser and image based surveys of European classical architecture, «ISPRS Journal of Photogrammetry and Remote Sensing», 76, pp. 89102.

Oxman R., Oxman R., 2014. Theories of the Digital in Architecture. Oxford: Routledge, 2014

Philippe ,E., Foster, A, 1978. A study of Lorenzo de' Medici's Villa at Poggio a Caiano, Yale University 1974, Michigan

Valero, E., Adan, A., Huber, D., Cerrada, C., 2011. Detection, modeling, and classification of moldings for automated reverse engineering of buildings from 3D data, Proceedings of the International Symposium on Automation and Robotics in Construction (ISARC). 